\title{
Fatty Acid Ethyl Esters Are Less Toxic Than Their Parent Fatty Acids Generated during Acute Pancreatitis
}

\author{
Krutika Patel, ${ }^{*}$ Chandra Durgampudi, ${ }^{\dagger}$ Pawan Noel, ${ }^{*}$ Ram N. Trivedi, ${ }^{*}$ Cristiane de Oliveira, ${ }^{*}$ and Vijay P. Singh*
}

From the Division of Gastroenterology and Hepatology, * Department of Medicine, Mayo Clinic, Scottsdale, Arizona; and the Department of Medicine, ${ }^{\dagger}$ University of Pittsburgh Medical Center, Pittsburgh, Pennsylvania

Accepted for publication November 19, 2015.

Address correspondence to Vijay P. Singh, M.D., Division of Gastroenterology and Hepatology, Mayo Clinic, Scottsdale, AZ 85259. E-mail: singh.vijay@mayo.edu.

\begin{abstract}
Although ethanol causes acute pancreatitis (AP) and lipolytic fatty acid (FA) generation worsens AP, the contribution of ethanol metabolites of FAs, ie, FA ethyl esters (FAEEs), to AP outcomes is unclear. Previously, pancreata of dying alcoholics and pancreatic necrosis in severe AP, respectively, showed high FAEEs and FAs, with oleic acid $(O A)$ and its ethyl esters being the most abundant. We thus compared the toxicities of FAEEs and their parent FAs in severe AP. Pancreatic acini and peripheral blood mononuclear cells were exposed to FAs or FAEEs in vitro. The triglyceride of OA (i.e., glyceryl tri-oleate) or OAEE was injected into the pancreatic ducts of rats, and local and systemic severities were studied. Unsaturated FAs at equimolar concentrations to FAEEs induced a larger increase in cytosolic calcium, mitochondrial depolarization, and necro-apoptotic cell death. Glyceryl tri-oleate but not OAEE resulted in $70 \%$ mortality with increased serum $O A$, a severe inflammatory response, worse pancreatic necrosis, and multisystem organ failure. Our data show that FAs are more likely to worsen AP than FAEEs. Our observations correlate well with the high pancreatic FAEE concentrations in alcoholics without pancreatitis and high FA concentrations in pancreatic necrosis. Thus, conversion of FAs to FAEE may ameliorate AP in alcoholics. (Am J Pathol 2016, 186: 874-884; http://dx.doi.org/10.1016/j.ajpath.2015.11.022)
\end{abstract}

Although fat necrosis has been associated with severe cases of pancreatitis for more than a century, ${ }^{1,2}$ and alcohol consumption is a well-known risk factor for acute pancreatitis (AP), only recently have we started understanding the mechanistic basis of these observations. ${ }^{4-7}$ High amounts of unsaturated fatty acids (UFAs) have been noted in the pancreatic necrosis and sera of severe AP (SAP) patients by multiple groups. ${ }^{8-12}$ These high UFAs seem pathogenically relevant because several studies show UFAs can cause pancreatic acinar injury or can worsen AP. ${ }^{11-14}$ Ethanol may play a role in AP by distinct mechanisms, ${ }^{3}$ including a worse inflammatory response to cholecystokinin, ${ }^{4}$ increased zymogen activation, ${ }^{15}$ basolateral enzyme release, ${ }^{16}$ sensitization to stress, ${ }^{7}$ FA ethyl esters (FAEEs), ${ }^{17}$ cytosolic calcium, ${ }^{18}$ and cell death. ${ }^{19}$

Because the nonoxidative ethanol metabolite of fatty acids (FAs), FAEEs, were first noted to be elevated in the pancreata of dying alcoholics, they have been thought to play a role in AP. ${ }^{17,19-22}$ Conclusive proof of the role of FAEEs in AP in comparison with their parent UFAs is lacking. Uncontrolled release of lipases into fat, whether in the pancreas or in the peritoneal cavity, may result in fat necrosis, UFA generation, which has been associated with SAP. ${ }^{11,12}$ Pancreatic homogenates were also noted to have an ability to synthesize FAEEs from FAs and ethanol, ${ }^{20,23}$ and the putative enzyme for this was thought to be a lipase. ${ }^{24,25}$ It has been shown that the FAEE synthase activity of the putative enzyme exceeds its lipolytic capacity by several fold. ${ }^{25}$

Triglyceride (TG) forms $>80 \%$ of the adipocyte mass, ${ }^{26-28}$ oleic acid (OA) being the most enriched FA. ${ }^{9,29}$ We recently showed that lipolysis of intrapancreatic TG worsens pancreatitis. ${ }^{11,12}$ Therefore, after noting the ability of the pancreas to cause lipolysis of TG into FAs and also to have high FAEE synthase activity

Supported by NIH grants RO1DK092460 and R01DK100358 and the Department of Army grant PR110417 (all to V.P.S.).

K.P., C.D., and P.N. contributed equally to this work.

Disclosures: None declared. 
and FAEE concentrations, we decided to compare the relative ability of FAEEs and their parent FAs to initiate deleterious signaling in pancreatitis and to investigate their impact on the severity of AP.

\section{Materials and Methods}

\section{Reagents}

Linoleic acid (LA), palmitic acid (PA), glyceryl tri-oleate (GTO), and oleic acid ethyl esters (OAEE; sold as ethyl oleate) were purchased from Sigma-Aldrich (St. Louis, MO). Palmitic acid ethyl esters (PAEE) and Linoleic acid ethyl esters (LAEE) were from Cayman Chemical (Ann Arbor, MI). For in vitro studies, these were all dissolved in dimethyl sulfoxide (DMSO; Sigma-Aldrich) as pure solutions, sonicated at $2 \times$ final concentration, and used at a final concentration of $0.5 \%$ DMSO for the in vitro studies. This concentration of DMSO has no effect on any of the markers tested over the duration of the study [eg, control lactate dehydrogenase (LDH) leakage without vehicle over 4 hours was $9.6 \% \pm 0.8 \%$ versus $9.4 \% \pm 1.2 \%$ in the $0.5 \%$ DMSO group]. Ketamine hydrochloride injection was from Fort Dodge Animal Health (Fort Dodge, IA), and xylazine injection (xylazine sterile solution $100 \mathrm{mg} / \mathrm{mL}$ ) was from Lloyd Laboratories (Shenandoah, IA). The rest of the reagents are detailed in the areas mentioning their use.

\section{Animal Work}

Male Wistar rats of 250 to $300 \mathrm{~g}$, purchased form Charles Rivers Laboratories (Wilmington, MA), were acclimatized for at least 2 days before use. These rats were housed with a 12-hour light-dark cycle, fed standard laboratory chow, and allowed to drink ad libitum until the night before the surgery, when they were deprived of food. After adequate anesthesia with $90 \mathrm{mg}$ ketamine/kg and $8 \mathrm{mg}$ xylazine $/ \mathrm{kg}$, intraperitoneally, under sterile precautions, either the TG of oleic acid (GTO) also known as triolein, or the ethyl esters (EE) of OA, ie, OAEE, also known as ethyl oleate (both dosed as $50 \mu \mathrm{L} / 100 \mathrm{~g}$ of body weight) were injected into the biliopancreatic duct in rats. The biliopancreatic duct was ligated after the injection. Postoperatively, animals were intramuscularly administered $100 \mathrm{mg}$ cefazolin/kg (WG Critical Care, Paramus, NJ) for infection prevention, buprenorphine SR (ZooPharm, Windsor, $\mathrm{CO}$; at $0.6 \mathrm{mg} / \mathrm{kg}$, i.p.) for pain management, and normal saline subcutaneously daily. These animals were followed up to 5 days for survival or were sacrificed at the time near mortality (moribund state). In addition, a separate group of animals in the OAEE group were sacrificed electively after 24 hours of AP induction to compare the severity with GTO, because this was the time when nearly all mortality was observed in the GTO group. On necropsy, serum and pancreata were harvested to study for various markers of pancreatitis initiation, histologic assessment, cytokine levels, lipotoxic mediators, and markers of end-organ injury, the details of which are described in
Materials and Methods. There were 10 to 12 animals in each group. All experiments were approved by the Institutional Animal Care and Use Committee at the University of Pittsburgh and the Mayo Clinic (Scottsdale, AZ).

\section{Acinar Harvest and in Vitro Assays}

Mice pancreatic acini were harvested, as described previously. ${ }^{30,31}$ Fresh acini were used for all assays. Viability, confirmed by Trypan blue exclusion, was $>95 \%$. Acini were exposed to FAs (LA, OA, PA) and their corresponding FAEEs (ie, LAEE, OAEE, PAEE) at concentrations relevant to human pancreatic debridement fluids. The human necrotic fluid collections contained $1235 \pm 412 \mu \mathrm{mol} / \mathrm{L}$ $\mathrm{OA}, 613 \pm 214 \mu \mathrm{mol} / \mathrm{L} \mathrm{PA}$, and $586 \pm 185 \mu \mathrm{mol} / \mathrm{L} \mathrm{LA}{ }^{32}$ Necrotic cell injury was assessed by LDH leakage, propidium iodide (PI) uptake (both as percentage of total), and adenosine triphosphate (ATP) levels of the pellets at the end of the incubation (4 hours). These were performed with colorimetric, fluorescence, or luminescence assay as described previously. ${ }^{33}$ LDH activity in the medium and PI uptake into the cells were measured and expressed as a percentage of total generated by lysis of cells with the use of $1 \%$ Triton X-100. ATP measured was normalized to untreated controls as $100 \%$. In addition, cell pellets were collected at 90 minutes and fractionated into cytosolic and mitochondrial fractions. These lysates were then probed for cytochrome $c$ oxidase IV, $\alpha$-tubulin, and cytochrome $c$ by Western blot analysis, as described further.

\section{Western Blot Analysis}

Cytosolic and mitochondrial cell fractions were homogenized in lysis buffer that contained various protease inhibitors (Complete, EDTA Free; Roche, Mannhein, Germany) and then normalized for $1 \mu \mathrm{g} / \mu \mathrm{L}$ protein after protein estimation with a Pierce protein assay kit (Thermo Fisher Scientific, Rockford, IL). Lysates were boiled (5 minutes) in Laemmli buffer that contained SDS and $\beta$-mercaptoethanol, loaded (10 $\mu \mathrm{g} / \mathrm{lane})$ on $12 \%$ polyacrylamide gels and underwent electrophoresis denaturing conditions (SDS-PAGE). Western blot analysis was performed by incubation with primary antibody cytochrome $c$ oxidase IV (dilution 1:2000; Invitrogen, Grand Island, NY), cytochrome $c$ (dilution 1:750; Cell Signaling Technology, Danvers, MA), and $\alpha$-tubulin (dilution 1:1000; Developmental Studies Hybridoma Bank, Iowa City, IA) and then probed with horseradish peroxidase-labeled corresponding secondary antibodies (dilution 1:10,000; Millipore Corp, Billerica, MA). Band intensity was visualized by chemiluminesence by using electrochemiluminescence plus Western blot detection kit (Amersham GE Healthcare, Buckinghamshire, UK).

\section{Calcium Imaging}

Calcium imaging was performed as described previously ${ }^{34,35}$ in acinar cells loaded with fura-2AM, adhered to glass 
coverslips, and imaged at $37^{\circ} \mathrm{C}$ on an Olympus IX81 inverted microscope (Olympus America Inc., Center Valley, PA) with a $20 \times 0.70$ NA objective and a QImaging Retiga EXi CCD camera (QImaging, Surrey, BC, Canada). The FAs and their EEs were added at the final indicated concentrations, and cytosolic calcium levels were determined by alternate excitation at $340 \mathrm{~nm}$ and $380 \mathrm{~nm}$, measuring emission at $510 \mathrm{~nm}$. Image acquisition was with the MetaMorph Imaging System (Molecular Devices, Sunnyvale, CA), using the MetaMorph software version 6.3 (Molecular Devices). The 340/380 emission ratio was averaged for 7 to 25 acini per field after background subtraction. Data are presented as means from at least four separate experiments.

\section{Mitochondrial Depolarization Measurement}

Acinar cells were loaded with 5,5',6,6'-tetrachloro-1,1',3,3'tetraethylbenzimidazolylcarbocyanine iodide (JC-1, $5 \mu \mathrm{g} / \mathrm{mL}$; Enzo Life Sciences, Farmingdale, NY) at $37^{\circ} \mathrm{C}$ for 15 minutes. After loading, the cells were washed twice and kept on ice until use. In a quartz cuvette, cells were stimulated with different agonists at the final indicated concentrations, and changes in mitochondrial inner membrane potential $(\Psi \mathrm{m})$ were determined by excitation at $515 \mathrm{~nm}$ and alternate measuring emission at 530 and $590 \mathrm{~nm}$ with the use of the F2100 Hitachi Fluorescence Spectrophotometer (Tokyo, Japan). A decrease in the JC-1 aggregate fluorescence at 590 $\mathrm{nm}$ and an increase in the fluorescence at $530 \mathrm{~nm}$ reflect depolarization. The 530/590 emission ratio was averaged, and data are presented as means from at least four separate experiments.

\section{Biochemical Assays}

Serum amylase, lipase, and blood urea nitrogen were measured according to the manufacturer's (Pointe Scientific Inc., Canton, MI) instructions on a ChemWell-T chemistry analyzer (Awareness Technology, Palm City, FL).

\section{FA Measurement}

Serum OA (C18:1) level was measured by performing nonesterified FA (NEFA) analysis with the use of gas chromatography, as described previously, ${ }^{11,12,35}$ on samples with adequate volumes (at least $25 \mu \mathrm{L}$ ).

\section{Evaluation of Pancreatic Necrosis and Special Stains}

Whole pancreas section slides stained by hematoxylin and eosin were examined by a trained morphologist (K.P.) blinded to the sample as described previously. ${ }^{12,35}$ In brief, all pancreatic parenchymal area was imaged with a $4 \times$ objective, and photographs were evaluated for acinar necrosis. Necrotic area and total acinar area were measured in pixels for each pancreas. Percentage of necrosis was reported as a percentage of total area for each pancreas. The results are depicted as bar graphs, showing means \pm SEM for each group. Terminal deoxynucleotidyl transferase-mediated dUTP nick-end labeling (TUNEL) staining was performed on paraffin sections of the lungs and kidneys and was quantified, as described previously. ${ }^{12}$

\section{Immunohistochemical Studies}

The horseradish-peroxidase immunohistochemical technique was used to detect myeloperoxidase (MPO) in paraffinembedded sections of lung tissue. In brief, after deparaffinization and antigen epitope retrieval, tissues were incubated with a primary rabbit polyclonal antibody against MPO (dilution 1:50; Abcam, Cambridge, MA), followed by application of horseradish peroxidase-conjugated (dilution 1:1000; Millipore Corp) secondary antibody. Staining was completed with chromogen incubation with 3-amino-9-ethylcarbazole substrate kit for peroxidase and hematoxylin QS nuclear counterstain (Vector Laboratories, Burlingame, CA). Quantification of MPO positivity was performed as percentage of 3-amino-9-ethylcarbazole-stained nuclear area to total nuclear area in the lung tissue, calculated by color thresh holding on Adobe Photoshop CS4 (San Jose, CA).

\section{Cytokine Assays}

Cytokine assays were performed on serum samples by fluorescence-based capture sandwich immunoassay (Luminex), using the MILLIPLEX MAP Rat Cytokine-Chemokine Magnetic beads panel (Millipore Corp). These samples were analyzed at the Luminex Core Facility of the University of Pittsburgh Cancer Institute.

\section{Flow Cytometry of Rodent PBMCs}

Rodent peripheral blood mononuclear cells (PBMCs) were incubated for 30 minutes at $37^{\circ} \mathrm{C}$ in serum-free RPMI 1640 media that contained $25 \mathrm{mmol} / \mathrm{L}$ HEPES either alone or with $10 \mu \mathrm{mol} / \mathrm{L}$ OA or OAEE. Cytotoxicity was evaluated by labeling cells with annexin V and PI according to the manufacturer's instructions for the fluorescein isothiocyanate-annexin $\mathrm{V}$ apoptosis detection kit (BD Pharmigen, San Diego, CA). Flow cytometry of labeled cells was performed on the BD LSR Fortessa Analyzer running the BD FACS Diva software version 8.0.1 (BD Biosciences, San Jose, CA). Acquisition of fluorescence signals was performed after adjusting for forward and side scatter voltages, selecting appropriate fluorochrome channels, and a minimum of 50,000 gated events per experimental condition were analyzed.

\section{Statistical Analysis and Graphic Representation}

Bar graphs or box plots were used to depict the data, which were collected as independent variables, whereas line graphs were used for continuous variables. All values are reported as means \pm SEM. Box plots and whisker plots are used in the 
A
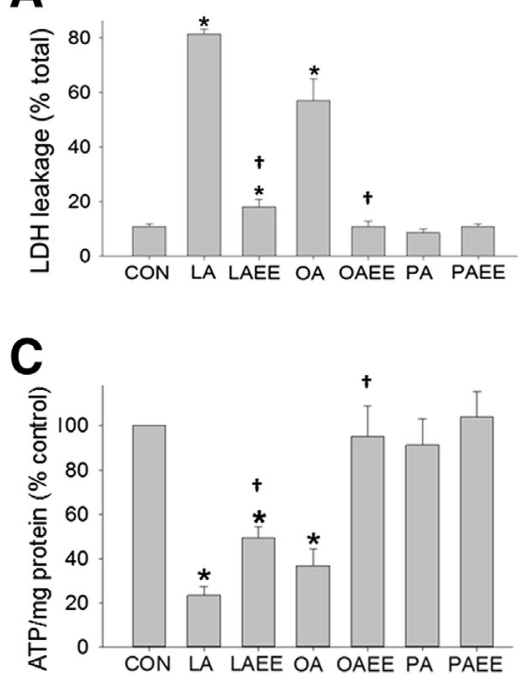

B

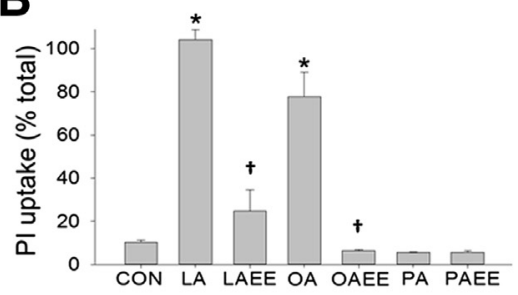

D

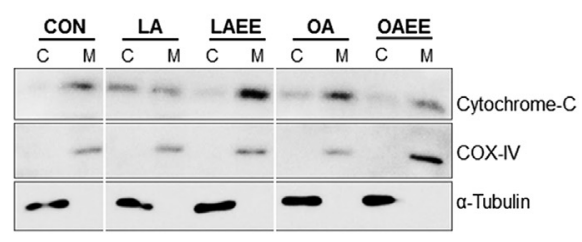

Figure 1 Fatty acids cause more cell death than their EEs. A and B: LDH leakage (A) and PI uptake (B) is increased compared with CONs in acini treated with unsaturated fatty acids $L A$ and $O A$ compared with LAEE and OAEE. C: LA and OA also cause decrease in ATP levels compared with their EEs. The saturated fatty acid PA does not cause any effect compared with its EE, PAEE. D: Western blot analysis for cytochrome $c$ shows a leakage of cytochrome $c$ from the $M$ compartment to the $C$ compartment in the presence of LA or OA. This intercompartment cytochrome $c$ leakage is absent in LAEE and OAEE. Loading controls, $\alpha$-tubulin for the $C$ compartment and COX-IV for the $M$ compartment, are equally present in all of the groups. Data are expressed as means \pm SEM. ${ }^{*} P<0.05$ versus CONs; ${ }^{\dagger} P<0.05$ versus $\mathrm{LA} / \mathrm{OA}$. ATP, adenosine triphosphate; C, cytosolic compartment; CON, control; COX, cytochrome $c$ oxidase; $\mathrm{EE}$, ethyl ester; LA linoleic acid; LDH, lactate dehydrogenase; $M$, mitochondrial compartment; OA, oleic acid; PA, palmitic acid; PI, propidium iodide. depiction of serum cytokines, in which mean (dotted line), median (solid line), 25th and 75th percentiles (two boxes), and 10th and 90th percentiles (whiskers) are depicted. All significance levels were evaluated at $P<0.05$ and were compared by the one-way analysis of variance versus controls or two-tailed $t$-test between the triolein (GTO) and OAEE groups. $P<0.05$ was considered statistically significant.

\section{Results}

\section{FAEEs Induce Less Acinar Injury Than the Parent FAs at Equimolar Concentrations}

To determine the relative toxicities of FAEEs and the parent NEFAs, $300 \mu \mathrm{mol} / \mathrm{L}$ of the most prevalent NEFAs in the human pancreatic necrosis collections ${ }^{11,20,32}$ were added at relevant concentrations to acinar cells, and LDH leakage was measured over 4 hours (Figure 1A). These NEFA concentrations used are within the range of those noted in human pancreatic necrosis collections. ${ }^{11,12,32}$ Although both UFAs (LA and OA) resulted in $>50 \%$ LDH leakage, their respective EEs (LAEE and OAEE) resulted in significantly less acinar injury. Because UFAs are known to eventually induce acinar necrosis, ${ }^{11-13}$ we measured PI uptake and noted a similar pattern (Figure 1B). As previously shown, ${ }^{11,13}$ the saturated FA (SFA) PA did not induce acinar injury, with its EE (PAEE) being similarly nontoxic. UFAs have been shown to result in acinar necrosis via ATP depletion by inhibition of mitochondrial complexes I and $\mathrm{V}^{11}$; we thus compared the ATP levels in acini treated with NEFA or their corresponding EEs. It has been previously shown that ATP levels drop in response to LA over 1 hour. ${ }^{35}$ Similar to the pattern of LDH leakage, and the previously published data, ${ }^{11,35}$ LA and $\mathrm{OA}$ resulted in significantly lower ATP levels, whereas their corresponding
EEs (LAEE and OAEE had higher levels (Figure 1C). We also noted cytochrome $c$ leakage to be more with the FAs than with the corresponding FAEEs (Figure 1D).

To explore this further, we studied early events in cell death signaling. We compared the effect of agents that induce cell death and their corresponding EEs on two widely published early cell death events, $\Psi \mathrm{m}$ and $\mathrm{Ca}_{\mathrm{i}}$ levels. As previously published, we noted maximal $\mathrm{Ca}_{\mathrm{i}}$ increase at $600 \mu \mathrm{mol} / \mathrm{L}$, which is in the range noted in human pancreatic necrosis collections. ${ }^{11,32}$ Consistent with the loss of $\Psi \mathrm{m}$ being associated with triggering cell death, there was a greater increase in the 530/590 emission ratio of JC-1 induced by LA and OA than by LAEE or OAEE (Figure 2, A and B) at equal concentrations. Similarly, LA and OA (Figure 2, C and D) did cause an increase in $\mathrm{Ca}_{\mathrm{i}}$, but LAEE and OAEE did not. The increase in $\mathrm{Ca}_{\mathrm{i}}$ induced by UFAs has been previously shown to be from a thapsigargin-sensitive intracellular store ${ }^{35}$ and not due to a detergent effect. Thus, the early loss of mitochondrial membrane potential triggers cell death, as supported by cytochrome $c$ leakage, which along with inhibition of complexes I and $\mathrm{V}$ and associated decrease in ATP levels, sustained increase in $\mathrm{Ca}_{\mathrm{i}}$, eventually resulting in worse necrosis induced by NEFAs than FAEEs.

\section{Intraductal Triolein Results in a Higher Serum Oleate and Mortality Than OAEE}

To test the in vivo relevance of the in vitro findings mentioned in the previous two paragraphs, we went ahead and compared the severity of pancreatitis induced by the TG of OA (which is the most abundant FA found in necrotic collections), ie, triolein (or GTO) or its EE, OAEE. We used the previously described model of pancreatitis involving direct administration of these agents into the pancreatic duct of lean rats. ${ }^{12}$ This simulates the lipolysis of visceral fat TG by the pancreatic lipases leaked into fat during pancreatitis. We have previously shown that the lipolysis of the 

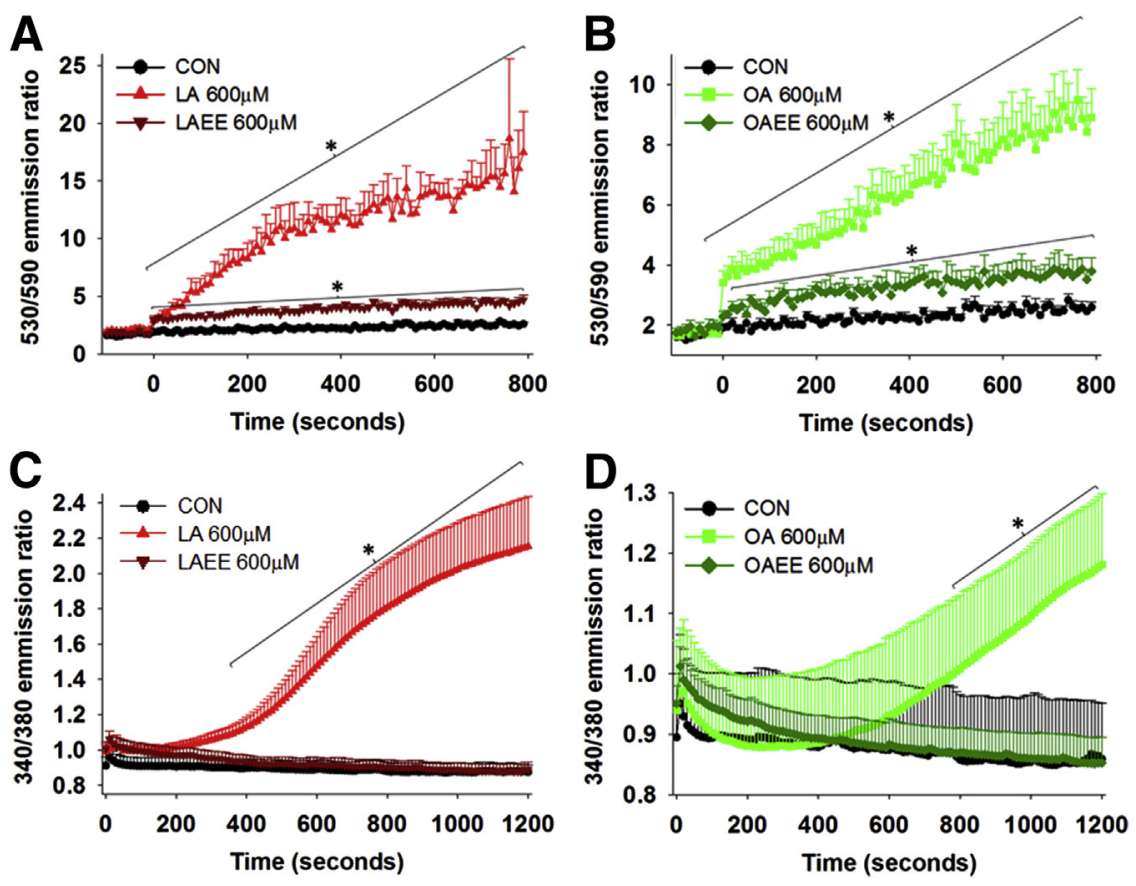

Figure 2 FAEEs affect mitochondrial membrane potential and cytosolic calcium levels less than FAs. A and B: All agents were added at zero second. LA and OA cause a significantly higher loss of mitochondrial membrane potential than their respective FAEEs, indicated by the increase in 530/ 590 emission ratio. C and D: Cytosolic calcium levels in Fura-2-loaded acini, measured by 340/ 380 emission ratio, show an increase in resting calcium by FAs, not FAEEs. Data are expressed as means \pm SEM. $n=4$ to 5 experiments. ${ }^{*} P<0.05$ versus the CON state. CON, control; EE, ethyl ester; FA, fatty acid; LA, linoleic acid; OA, oleic acid. injected TG and not its mere injection or presence in the pancreas, results in adverse outcomes. ${ }^{12}$

Consistent with the lipolysis of injected GTO, there was an increase in serum OA which was significantly higher than in the group receiving OAEE (Figure $3 \mathrm{~A}$ ). This was associated with a significantly higher mortality $(70 \% ; P=0.003)$ in the GTO group within 24 hours of inducing pancreatitis compared with no mortality being noted in the OAEE group over the 5 days these rats were followed (Figure 3B). These findings are consistent with our recent work showing that lipolysis of unsaturated TG worsens AP. ${ }^{12}$

\section{Intraductal OAEE Results in Lesser Pancreatic Injury Than Triolein}

Both local and systemic injury may contribute to the severity of pancreatitis. We first compared the effect of GTO and OAEE on local injury. There was gross evidence of hemorrhagic pancreatitis in the pancreata of rats receiving GTO but not OAEE (Figure 4, A-C). Morphometric analysis showed GTO to result in $62.4 \% \pm 5.1 \%$ necrosis, which was significantly more than that induced by OAEE $(11 \% \pm 2.8 \% ; P<0.001)$ (Figure 4, D and E). This was associated with significantly lower serum amylase and lipase in the OAEE group versus the GTO group (Figure 4, F and G). These findings are consistent with the in vitro findings that FAEEs are less toxic than the parent UFAs.

\section{Intraductal OAEE Results in Lesser Systemic Injury Than Triolein}

Because systemic injury occurs during SAP, we compared systemic injury markers in response to GTO and OAEE.
GTO caused a higher serum IL-1 $\beta$, IL-6, IL-18, and keratinocyte chemoattractant-growth-regulated oncogene than OAEE (Figure 5, A-D). Similarly, although we noted a low level of MPO positivity in control lungs as has previously been shown by many groups, ${ }^{36-40}$ there was a significantly higher MPO increase induced in the GTO-administered group than in the OAEE group (Figure 5E). GTO-treated but not OAEE-treated rats had a significant increase in TUNEL $^{+}$cells in the lungs (Figure 6A). The findings in the GTO-treated group are similar to those induced in OAinduced acute respiratory distress syndrome. ${ }^{41,42}$ GTO treated rats also had renal failure evidenced by elevated serum blood urea nitrogen and $\mathrm{TUNEL}^{+}$cells in the kidney tubules at the time of necropsy (Figure 6B). Findings of drop out necrosis in these tubules supported progression to acute tubular necrosis. Flow cytometry of PBMCs showed that treatment with $10 \mu \mathrm{mol} / \mathrm{L} \mathrm{OA}$ resulted in significantly
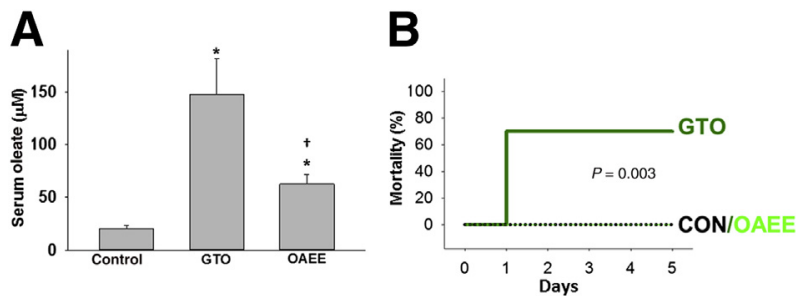

Figure 3 Intraductal injection of triolein causes higher rate of mortality and serum $0 \mathrm{~A}$ concentrations. A: Bar graphs of serum oleate level showing a significant increase in its concentrations with intraductal injection of triolein and OAEE. OAEE causes a significantly lesser increase compared with triolein. B: Kaplan-Meyer mortality curves show $70 \%$ mortality with the GTO group versus no mortality in the OAEE group. Data are expressed as means \pm SEM. ${ }^{*} P<0.05$ versus the $\mathrm{CON} ;{ }^{\dagger} P<0.05$ versus triolein (GTO) group. CON, control; $\mathrm{EE}$, ethyl ester; GTO, glyceryl tri-oleate; $\mathrm{OA}$, oleic acid. 


\section{A Control}

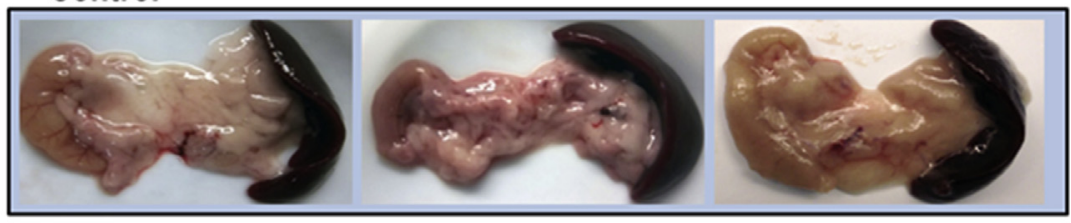

B

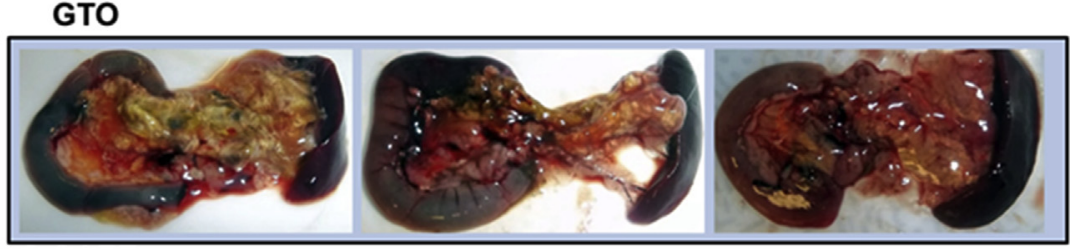

C

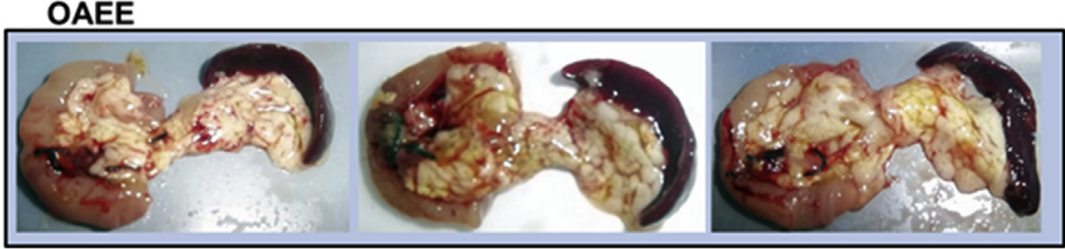

D

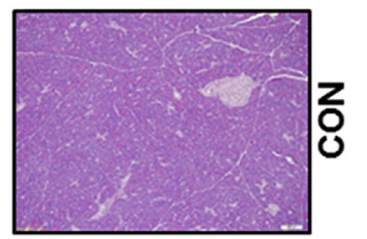

E

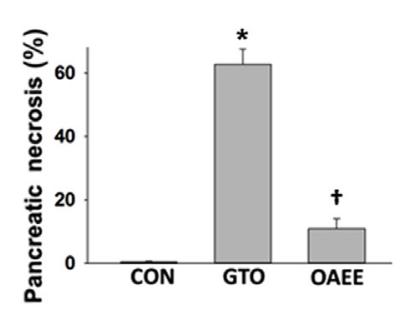

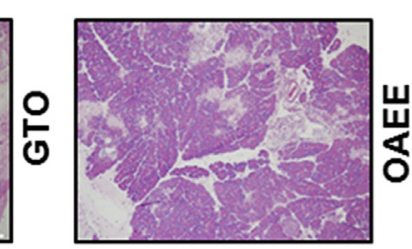

G
$\mathbf{F}$

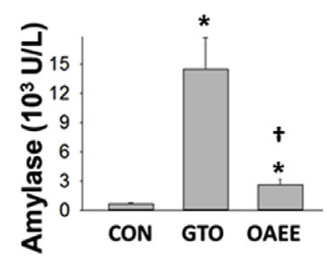

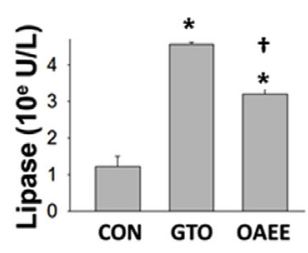

Figure 4 Triolein causes severe hemorrhagic necrotizing pancreatitis. A-E: Gross appearance $(\mathbf{A}-\mathbf{C})$ and hematoxylin and eosin-stained sections (D) of the pancreas in CONs (A and D), intraductal triolein (B and $\mathbf{D}$ ), and OAEE (C and $\mathbf{D})$. Intraductal injection of GTO causes significant hemorrhage and necrosis (B, D, and $\mathbf{E}$ ) compared with the milder necrosis and no hemorrhage in $\mathrm{OAEE}(\mathbf{C}, \mathbf{D}$, and $\mathbf{E})$. $\mathbf{F}$ and $\mathbf{G}$ : OAEE caused a lesser increase in amylase and lipase than GTO. Data are expressed as means \pm SEM. ${ }^{*} P<0.05$ compared with CONs; ${ }^{\dagger} P<0.05$ compared with GTO. Original magnification, $\times 10$ (D). CON, control; GT0, glyceryl tri-oleate $\mathrm{OAEE}$, oleic acid ethyl ester. more necro-apoptotic injury than in response to OAEE (Figure 6, C-F). These results show that OAEE is less toxic to PBMCs and renal tubules and does not cause lung injury in contrast to its parent FA, OA.

\section{Discussion}

In this study, we compared the ability of FAEEs and their parent FAs to induce cell injury in vitro and during AP in vivo. Adipocytes are increased in obesity, which many studies show is a risk factor for SAP. ${ }^{43-50}$ Stored TG forms $>80 \%$ of the adipocyte mass. ${ }^{26-28}$ Because FAEEs are metabolites of ethanol, which is a common cause of AP, this study helps understand the role of FAEEs in AP compared with FAs generated from visceral fat lipolysis. With the use of the TG form of the most abundant FA found in pancreatic necrosis collections, ie, OA or its EE (OAEE), we find that the FAEE causes milder acinar injury and pancreatitis than the parent UFA; and, with the use of FAs in vitro at concentrations within the range of pancreatic necrosis collections, we note them to be more potent than their EEs in inducing an increase in $\mathrm{Ca}_{\mathrm{i}}$, loss of $\Psi \mathrm{m}$, decrease in ATP, cytochrome $c$ leakage, and necrotic cell death. These findings shed light on the role FAEEs may play in AP.

The historic first report that measured FAEEs in humans analyzed tissues from acutely intoxicated alcoholics (blood ethanol concentration, $>80 \mathrm{mg} / \mathrm{dL}$ ) dying from an accident, homicide, a nonalcohol-related natural cause, or alcoholic liver disease. ${ }^{20}$ Although adipose tissue and pancreas of these individuals had the highest levels of FAEEs, none of them had pancreatitis. Ethyl oleate was reported to be the most abundant FAEE in pancreata of humans and rodents exposed to ethanol. ${ }^{20,23}$ When supplied OA and ethanol, the pancreas synthesizes FAEEs at the highest rate compared with other tissue. ${ }^{20}$ This activity is noted in pancreatic homogenates in the presence of ethanol and after ethanol infusion $^{51,52}$ and may exceed the lipolytic capacity of the putative enzyme by $>60$-fold. ${ }^{25}$ This suggests that in the presence of sufficient ethanol, FAs may be converted to FAEEs in vivo. 

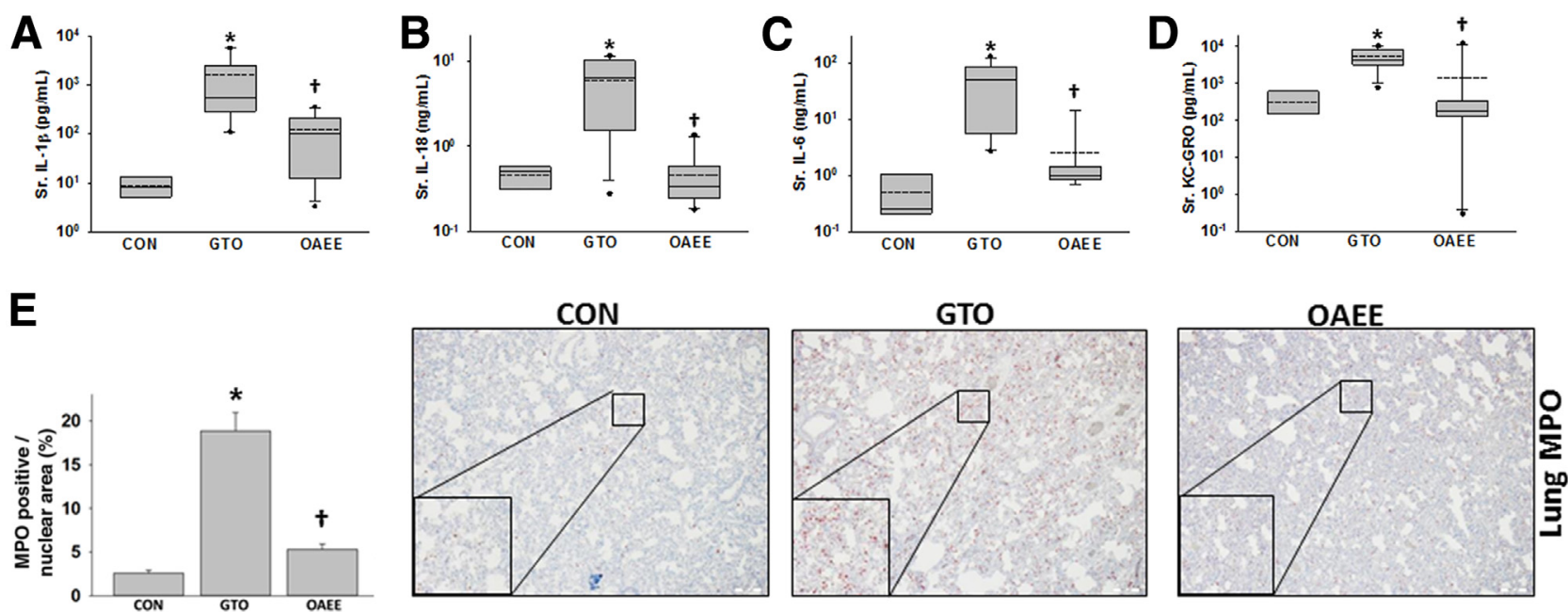

Figure 5 Triolein administration causes a worse cytokine response and inflammation compared with OAEE. A-D: Box plots depicting cytokines IL-1ß (A), IL-18 (B), IL-6 (C), and KC-GRO (D) show significant increase in the group administered triolein intraductally compared with CONs. Administration of OAEE significantly reduces these cytokines. E: $\mathrm{MPO}^{+}$cells are significantly increased in the GTO group versus the 0AEE group. ${ }^{*} P<0.05$ compared with CONs; ${ }^{\dagger} P<0.05$ compared with GTO. Original magnification: $\times 20(\mathrm{E}) ; \times 60$ (insets). CON, control; KC-GRO, keratinocyte chemoattractant - growth-regulated oncogene; GT0, glyceryl tri-oleate; MPO, myeloperoxidase; OAEE, oleic acid ethyl ester; Sr., serum.

Our current study clearly shows that FAEEs are less toxic than their parent UFAs at equivalent concentrations. The concentrations chosen mirror those in human pancreatic necrosis collections. ${ }^{11,12,32}$ This partly explains the high levels of FAEEs noted in the tissues of alcoholics without pancreatitis and why only a minority of alcoholics may develop pancreatitis ${ }^{53,54}$ despite high FAEEs in the pancreas. In contrast, lipolytic FA generation universally exacerbates pancreatitis to a lethal disease in the mechanistically distinct IL-12/IL-18, ${ }^{11}$ biliary, ${ }^{12}$ rat,${ }^{32}$ and mouse $^{55}$ caerulein models. ${ }^{11,12}$

Ethanol has diverse effects on AP outcomes in rodents. In some studies ethanol administration did not worsen pancreatitis ${ }^{56}$ but it enhanced exocrine secretion along with increasing plasma cholecystokinin levels. ${ }^{57}$ Ethanol may cause AP when co-administered with caerulein at doses that are one-tenth the highest caerulein dose used to induce pancreatitis, ${ }^{4}$ but which is still in the supraphysiologic range. When co-administered with a high-fat diet, chronic ethanol administration increased the fragility of lysosomal and zymogen membranes ${ }^{58,59}$ and resulted in chronic pancreatitis in $<30 \%$ animals. Interestingly, although most studies show FAEEs to be more toxic than in ethanol alone, ${ }^{17}$ separate studies show that infusion of FAEEs causes relatively mild changes (pancreatic edema, trypsinogen activation, vacuolization $)^{19}$ compared with UFAs (eg, OA), which when infused cause acute respiratory distress syndrome ${ }^{41,42,60-62}$ and renal injury, ${ }^{63,64}$ components of multisystem organ failure in SAP.

Studies by Criddle et $\mathrm{al}^{17}$ over the past decade have contributed significantly to our current understanding of the role of FAEEs in pancreatitis. Their seminal study in 2004 showed palmitoleic acid (POA) and its EE (POAEE) to cause a sustained increase in cytosolic calcium and to induce calcium-dependent cell death within the first hour of exposure. The role on calcium in early cell death induced by FAs was subsequently confirmed by us. ${ }^{11}$ However, we also noted that the amount of cell death within the first hour was small compared with the $>80 \%$ necrosis that occurred over the subsequent 4 hours and was insensitive to calcium chelation. ${ }^{11}$ In 2006 Criddle et $\mathrm{al}^{21}$ showed that FAEEs induced necrosis via conversion to FAs by an esterase sensitive to bis-(4-nitrophenyl) phosphate. However, the esterase so far has not been characterized, and the influence of bis-(4-nitrophenyl) phosphate on its activity was not measured in the study. Their study also showed that in most cases POA was toxic at one-half the dose of POAEE. ${ }^{21}$

The putative enzyme responsible for FAEE generation has remained elusive. The enzyme was mostly referred to as carboxylesterase $^{25}$ or cholesterol esterase in the 1990s. ${ }^{25}$ It was later proposed that formation of FAEEs is catalyzed by both an acyl-CoA:ethanol O-acyltransferase and a FAEE synthase which use FAs and acyl-CoA as substrates, respectively. ${ }^{65}$ Subsequently, this enzyme that has its first 15 amino acids identical to pancreatic cholesterol esterase ${ }^{66}$ was noted to be sensitive to inhibitors of serine proteases. ${ }^{67}$ In 2005 polymorphisms in the carboxyl ester lipase gene were noted to be associated with the risk of developing alcoholic pancreatitis.

In 2014, ${ }^{22}$ Criddle et al ${ }^{17}$ in contrast to their 2004 study noted that POA in most cases did not induce a sustained increase in cytosolic calcium. In addition, in contrast to their 2006 study which showed FAEE cytotoxicity depends on their conversion to $\mathrm{FAs}^{21}$; their 2014 study $^{22}$ showed this to depend on the conversion of POA to POAEE. This increase in cytosolic calcium and severity of pancreatitis were significantly reduced with the agent 3-benzyl-6-chloro-2-pyrone (3-BCP), a generic serine protease inhibitor, ${ }^{6,69}$ which they proposed 
A

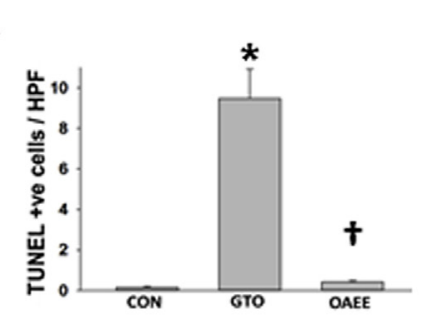

B

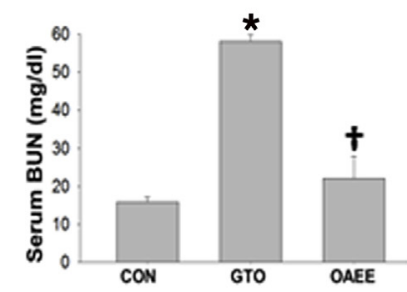

CON
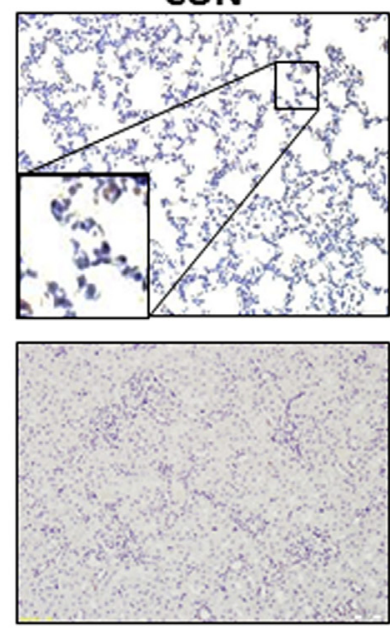
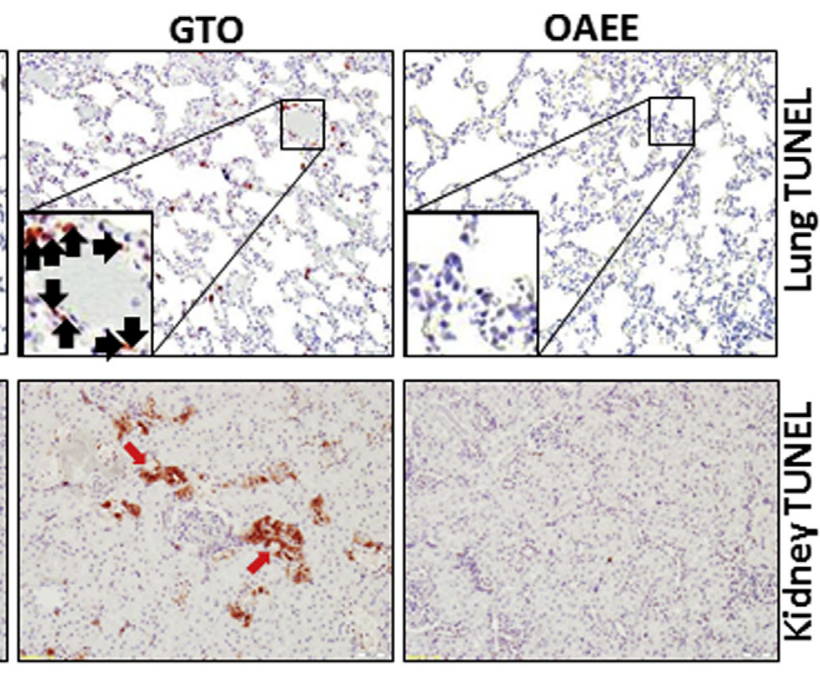

C
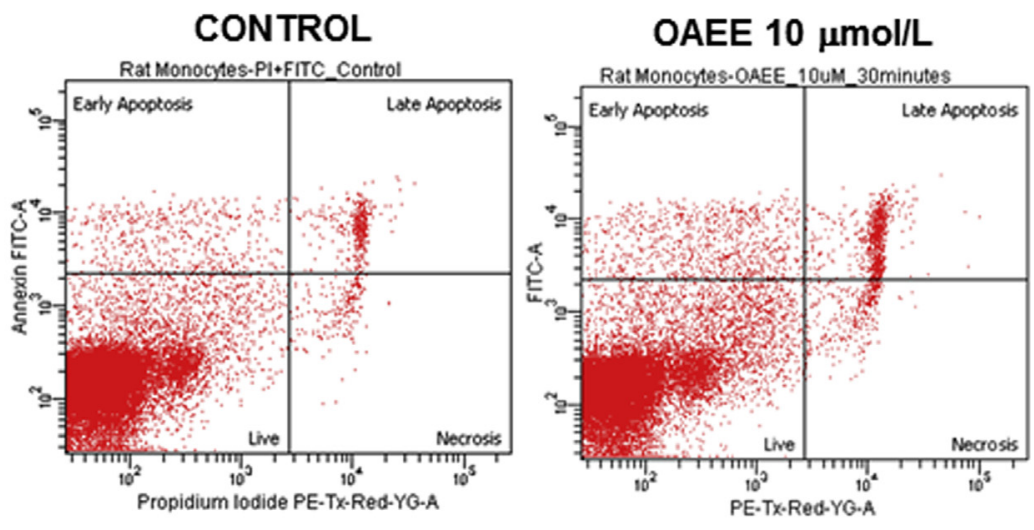

OAEE $10 \mu \mathrm{mol} / \mathrm{L}$
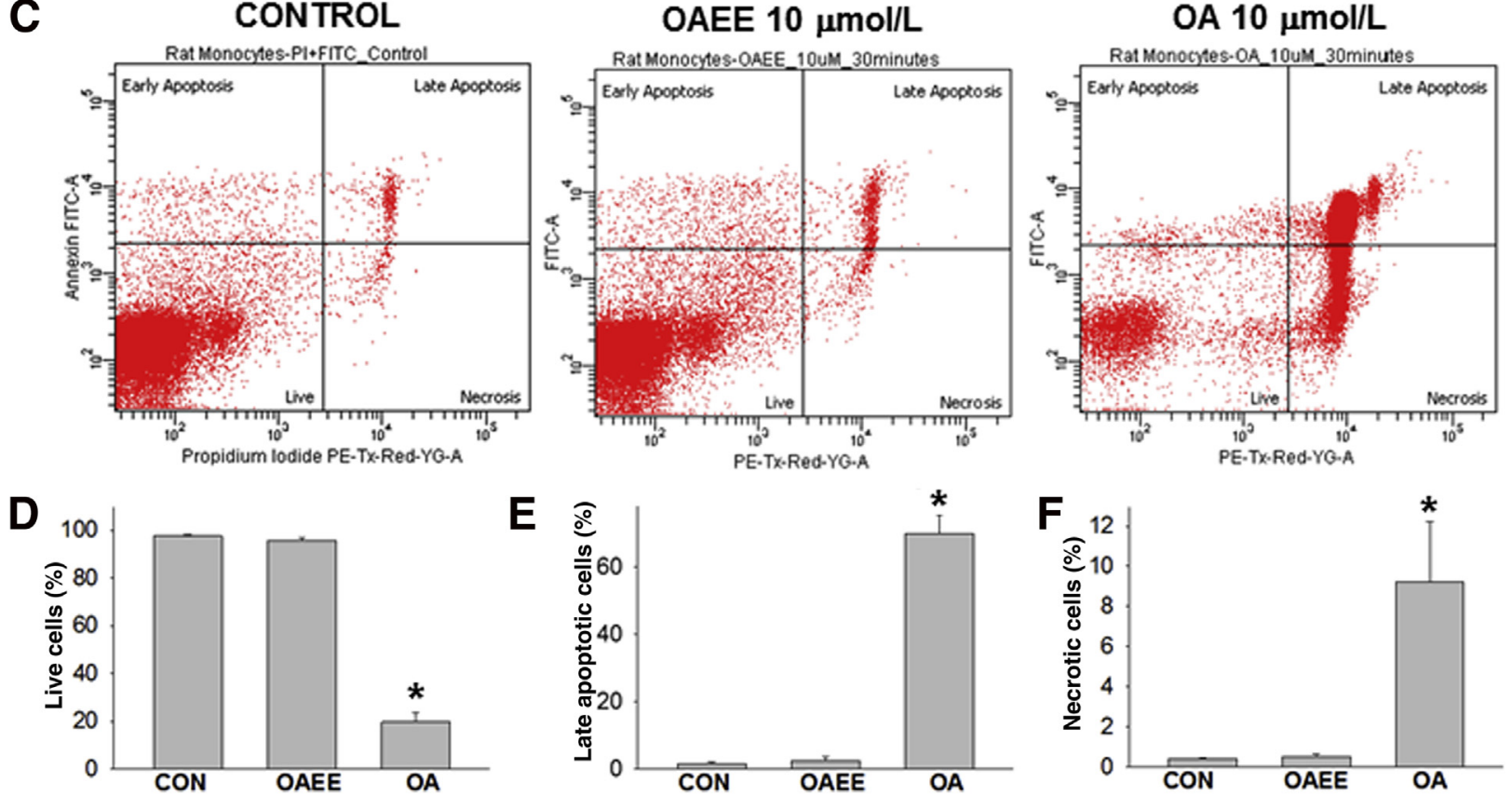

Figure 6 Triolein causes worse systemic injury compared with OAEE. A: Presence of TUNEL $^{+}$cells (inset, black arrows) in lungs are significantly higher in the GTO group than the OAEE group. B: Intraductal GTO also causes a significant increase in BUN and TUNEL cells in the kidney tubules. Representative TUNEL-stained image for each condition is shown to the right of the bar graphs (A and B). C-F: Peripheral blood mononuclear cells treated with $0 \mathrm{~A}$ show a significant decrease in live cells $(\mathbf{C}$ and $\mathbf{D})$ and an increase in late apoptotic cells $(\mathbf{C}$ and $\mathbf{E})$ and necrotic cells $(\mathbf{C}$ and $\mathbf{F})$ compared with OAEE at equimolar amounts $(10 \mu \mathrm{mol} / \mathrm{L}) .{ }^{*} P<0.05$ compared with CONs; ${ }^{\dagger} P<0.05$ compared with GT0. Original magnification: $\times 40$ (A); $\times 20$ (B); $\times 100$ (insets). BUN, blood urea nitrogen; CON, control; EE, ethyl ester; FITC, fluorescein isothiocyanate; GT0, glyceryl tri-oleate; HPF, high power field; OA, oleic acid; PI, propidium iodide; TUNEL, terminal deoxynucleotidyl transferase-mediated dUTP nick-end labeling.

to be a specific FAEE synthase/carboxyl ester lipase inhibitor. $^{22}$

These recent findings published by Criddle et $\mathrm{al}^{22}$ partly differ from our current work and their earlier studies. ${ }^{17,21}$ In our current work, similar to their 2006 study, we note FAEEs to be less toxic than the parent FAs. In addition, the following points help resolve differences. i) Previous work ${ }^{68}$ has shown 3-BCP to also be an inhibitor of serine esterases such as chymotrypsin, ${ }^{69} \alpha$-lytic protease, pig liver elastase, and cholinesterase, some of which have been implicated in initiating or worsening pancreatitis. Thus, this broad inhibitory effect of 3-BCP may contribute to its protection. ii) Carboxyl ester lipase is a pancreatic lipase, which is involved in the lipotoxic AP exacerbation in the mechanistically distinct biliary $^{12}$ and IL-12 + IL-18 models. ${ }^{11}$ Inhibition of lipases by 3 -BCP thus may contribute to the amelioration noted in their study. iii) As we note, FAEEs do cause cell death and pancreatitis, but it is substantially milder than from the parent FAs. iv) The pattern of necrosis noted by intraperitoneal administration of FAEEs or FAs + ethanol $^{22}$ shows this to be localized to the edges of the lobules, with relative sparing of acinar cells in the center, 
suggesting a local effect from the relatively large amounts of FAs/ethanol/FAEEs which were delivered into the peritoneal cavity.

Interestingly, a literature review of the roles of FAEEs also reveals their benign aspects. These include i) their levels being elevated in the pancreas of alcoholics without AP, ${ }^{20}$ and ii) FAEEs are used in treating hypertriglyceridemia. These include the Food and Drug Administration-approved EEs of eicosapentaenoic acid and docosahexaenoic acid, ${ }^{70}$ the parent FAs of which are as toxic to acinar cells as LA/OA (unpublished data). iii) Chronic OAEE administration to rats ( 3 months $)^{71}$ and humans ${ }^{72}$ does not cause toxicity.

The above-mentioned studies, along with evidence that i) high FA levels are noted in the sera ${ }^{8,10}$ and pancreatic necrosis debridement $^{9,11}$ of patients with SAP; ii) previous studies show the pancreatic toxicity of FAs ${ }^{11,13}$; iii) the ability of pancreatic tissue to rapidly form FAEEs, when supplied ethanol and $\mathrm{FAs}^{20}$; iv) high pancreatic FAEE concentrations in alcoholics without pancreatitis; and v) this study showing that FAEEs are less toxic than their parent FAs, suggests that the formation of FAEEs is a protective mechanism to detoxify FAs. In summary, the conversion of FAs to FAEEs in alcoholics may play a protective role in AP.

\section{Acknowledgments}

V.P.S. designed and conceptualized the study; K.P., C.D., P.N., R.N.T., and C.d.O. acquired the data; K.P., C.D., P.N., C.d.O., and V.P.S. analyzed and interpreted the data; K.P. and V.P.S. wrote the manuscript; C.D., P.N., and V.P.S. revised the manuscript; K.P., P.N., C.d.O., and V.P.S. performed the statistical analysis; V.P.S. supported and supervised the study.

\section{References}

1. Fitz RH: Acute pancreatitis: a consideration of pancreatic hemorrhage, hemorrhagic, suppurative, and gangrenous pancreatitis, and of disseminated fat-necrosis. Boston, MA, Cupples and Hurd Publishers, 1889

2. Hotchkiss LW: VIII. Acute pancreatitis with very extensive fat necrosis. Ann Surg 1912, 56:111-117

3. Pandol SJ, Raraty M: Pathobiology of alcoholic pancreatitis. Pancreatology 2007, 7:105-114

4. Pandol SJ, Periskic S, Gukovsky I, Zaninovic V, Jung Y, Zong Y, Solomon TE, Gukovskaya AS, Tsukamoto H: Ethanol diet increases the sensitivity of rats to pancreatitis induced by cholecystokinin octapeptide. Gastroenterology 1999, 117:706-716

5. Kubisch CH, Gukovsky I, Lugea A, Pandol SJ, Kuick R, Misek DE Hanash SM, Logsdon CD: Long-term ethanol consumption alters pancreatic gene expression in rats: a possible connection to pancreatic injury. Pancreas 2006, 33:68-76

6. Lam PP, Cosen Binker LI, Lugea A, Pandol SJ, Gaisano HY: Alcohol redirects CCK-mediated apical exocytosis to the acinar basolateral membrane in alcoholic pancreatitis. Traffic 2007, 8 : 605-617

7. Lugea A, Tischler D, Nguyen J, Gong J, Gukovsky I, French SW, Gorelick FS, Pandol SJ: Adaptive unfolded protein response attenuates alcohol-induced pancreatic damage. Gastroenterology 2011, 140: 987-997
8. Domschke S, Malfertheiner P, Uhl W, Buchler M, Domschke W: Free fatty acids in serum of patients with acute necrotizing or edematous pancreatitis. Int J Pancreatol 1993, 13:105-110

9. Panek J, Sztefko K, Drozdz W: Composition of free fatty acid and triglyceride fractions in human necrotic pancreatic tissue. Med Sci Monit 2001, 7:894-898

10. Sztefko K, Panek J: Serum free fatty acid concentration in patients with acute pancreatitis. Pancreatology 2001, 1:230-236

11. Navina S, Acharya C, DeLany JP, Orlichenko LS, Baty CJ, Shiva SS, Durgampudi C, Karlsson JM, Lee K, Bae KT, Furlan A, Behari J, Liu S, McHale T, Nichols L, Papachristou GI, Yadav D, Singh VP: Lipotoxicity causes multisystem organ failure and exacerbates acute pancreatitis in obesity. Sci Transl Med 2011, 3: $107 \mathrm{ra} 110$

12. Durgampudi C, Noel P, Patel K, Cline R, Trivedi RN, DeLany JP, Yadav D, Papachristou GI, Lee K, Acharya C, Jaligama D, Navina S, Murad F, Singh VP: Acute lipotoxicity regulates severity of biliary acute pancreatitis without affecting its initiation. Am J Pathol 2014, 184:1773-1784

13. Mossner J, Bodeker H, Kimura W, Meyer F, Bohm S, Fischbach W: Isolated rat pancreatic acini as a model to study the potential role of lipase in the pathogenesis of acinar cell destruction. Int J Pancreatol 1992, 12:285-296

14. Paye F, Presset O, Chariot J, Molas G, Roze C: Role of nonesterified fatty acids in necrotizing pancreatitis: an in vivo experimental study in rats. Pancreas 2001, 23:341-348

15. Lu Z, Karne S, Kolodecik T, Gorelick FS: Alcohols enhance caerulein-induced zymogen activation in pancreatic acinar cells. Am J Physiol Gastrointest Liver Physiol 2002, 282:G501-G507

16. Cosen-Binker LI, Lam PP, Binker MG, Reeve J, Pandol S, Gaisano HY: Alcohol/cholecystokinin-evoked pancreatic acinar basolateral exocytosis is mediated by protein kinase $\mathrm{C}$ alpha phosphorylation of Munc18c. J Biol Chem 2007, 282: 13047-13058

17. Criddle DN, Raraty MG, Neoptolemos JP, Tepikin AV, Petersen OH, Sutton R: Ethanol toxicity in pancreatic acinar cells: mediation by nonoxidative fatty acid metabolites. Proc Natl Acad Sci U S A 2004, 101:10738-10743

18. Criddle DN, Sutton R, Petersen OH: Role of $\mathrm{Ca} 2+$ in pancreatic cell death induced by alcohol metabolites. J Gastroenterol Hepatol 2006, 21(Suppl 3):S14-S17

19. Werner J, Laposata M, Fernandez-del Castillo C, Saghir M, Iozzo RV, Lewandrowski KB, Warshaw AL: Pancreatic injury in rats induced by fatty acid ethyl ester, a nonoxidative metabolite of alcohol. Gastroenterology 1997, 113:286-294

20. Laposata EA, Lange LG: Presence of nonoxidative ethanol metabolism in human organs commonly damaged by ethanol abuse. Science 1986, 231:497-499

21. Criddle DN, Murphy J, Fistetto G, Barrow S, Tepikin AV, Neoptolemos JP, Sutton R, Petersen OH: Fatty acid ethyl esters cause pancreatic calcium toxicity via inositol trisphosphate receptors and loss of ATP synthesis. Gastroenterology 2006, 130: $781-793$

22. Huang W, Booth DM, Cane MC, Chvanov M, Javed MA, Elliott VL, Armstrong JA, Dingsdale H, Cash N, Li Y, Greenhalf W, Mukherjee R, Kaphalia BS, Jaffar M, Petersen OH, Tepikin AV, Sutton R, Criddle DN: Fatty acid ethyl ester synthase inhibition ameliorates ethanol-induced $\mathrm{Ca} 2+$-dependent mitochondrial dysfunction and acute pancreatitis. Gut 2014, 63: 1313-1324

23. Laposata M, Kabakibi A, Walden MP, Cluette-Brown JE, Nanji AA, Refaai MA, Werner J, Nanji AA: Differences in the fatty acid composition of fatty acid ethyl esters in organs and their secretions. Alcohol Clin Exp Res 2000, 24:1488-1491

24. Lange LG: Nonoxidative ethanol metabolism: formation of fatty acid ethyl esters by cholesterol esterase. Proc Natl Acad Sci U S A 1982, 79:3954-3957 
25. Riley DJ, Kyger EM, Spilburg CA, Lange LG: Pancreatic cholesterol esterases. 2. Purification and characterization of human pancreatic fatty acid ethyl ester synthase. Biochemistry 1990, 29:3848-3852

26. Ren J, Dimitrov I, Sherry AD, Malloy CR: Composition of adipose tissue and marrow fat in humans by $1 \mathrm{H}$ NMR at 7 Tesla. J Lipid Res 2008, 49:2055-2062

27. Thomas LW: The chemical composition of adipose tissue of man and mice. Q J Exp Physiol Cogn Med Sci 1962, 47:179-188

28. Garaulet M, Hernandez-Morante JJ, Lujan J, Tebar FJ, Zamora S: Relationship between fat cell size and number and fatty acid composition in adipose tissue from different fat depots in overweight/obese humans. Int J Obes (Lond) 2006, 30:899-905

29. Pinnick KE, Collins SC, Londos C, Gauguier D, Clark A, Fielding BA: Pancreatic ectopic fat is characterized by adipocyte infiltration and altered lipid composition. Obesity (Silver Spring) 2008, 16:522-530

30. Singh VP, Bhagat L, Navina S, Sharif R, Dawra RK, Saluja AK: Protease-activated receptor-2 protects against pancreatitis by stimulating exocrine secretion. Gut 2007, 56:958-964

31. Singh VP, Saluja AK, Bhagat L, Hietaranta AJ, Song A, Mykoniatis A, Van Acker GJ, Steer ML: Serine protease inhibitor causes F-actin redistribution and inhibition of calcium-mediated secretion in pancreatic acini. Gastroenterology 2001, 120:1818-1827

32. Noel P, Patel K, Durgampudi C, Trivedi RN, de Oliveira C, Crowell MD, Pannala R, Lee K, Brand R, Chennat J, Slivka A, Papachristou GI, Khalid A, Whitcomb DC, DeLany JP, Cline RA, Acharya C, Jaligama D, Murad FM, Yadav D, Navina S, Singh VP: Peripancreatic fat necrosis worsens acute pancreatitis independent of pancreatic necrosis via unsaturated fatty acids increased in human pancreatic necrosis collections. Gut 2014, 65:100-111

33. Singh VP, Bren GD, Algeciras-Schimnich A, Schnepple D, Navina S, Rizza SA, Dawra RK, Saluja AK, Chari ST, Vege SS, Badley AD: Nelfinavir/ritonavir reduces acinar injury but not inflammation during mouse caerulein pancreatitis. Am J Physiol Gastrointest Liver Physiol 2009, 296:G1040-G1046

34. Mishra V, Cline R, Noel P, Karlsson J, Baty CJ, Orlichenko L, Patel K, Trivedi RN, Husain SZ, Acharya C, Durgampudi C, Stolz DB, Navina S, Singh VP: Src dependent pancreatic acinar injury can be initiated independent of an increase in cytosolic calcium. PLoS One 2013, 8:e66471

35. Acharya C, Cline RA, Jaligama D, Noel P, Delany JP, Bae K, Furlan A, Baty CJ, Karlsson JM, Rosario BL, Patel K, Mishra V, Dugampudi C, Yadav D, Navina S, Singh VP: Fibrosis reduces severity of acute-on-chronic pancreatitis in humans. Gastroenterology 2013, 145:466-475

36. de-Madaria E, del Mar Frances M, Gea-Sorli S, Gutierrez LM, Viniegra S, Perez-Mateo M, Closa D, Lopez-Font I: Role of proteaseactivated receptor 2 in lung injury development during acute pancreatitis in rats. Pancreas 2014, 43:895-902

37. Ren JD, Xing YJ, Fan KH, Yu BT, Jin WH, Jiang Y, Jing L, Wu XC, Wang SH, Wu J, Chen H: Pharmacological blockade of the MaxiK channel attenuates experimental acute pancreatitis and associated lung injury in rats. Int Immunopharmacol 2014, 21:220-224

38. Schnekenburger J, Schick V, Kruger B, Manitz MP, Sorg C, Nacken W, Kerkhoff C, Kahlert A, Mayerle J, Domschke W, Lerch MM: The calcium binding protein S100A9 is essential for pancreatic leukocyte infiltration and induces disruption of cell-cell contacts. J Cell Physiol 2008, 216:558-567

39. Sharif R, Dawra R, Wasiluk K, Phillips P, Dudeja V, Kurt-Jones E, Finberg R, Saluja A: Impact of toll-like receptor 4 on the severity of acute pancreatitis and pancreatitis-associated lung injury in mice. Gut 2009, 58:813-819

40. Carvalho AC, Sousa RB, Franco AX, Costa JV, Neves LM, Ribeiro RA, Sutton R, Criddle DN, Soares PM, de Souza MH: Protective effects of fucoidan, a P- and L-selectin inhibitor, in murine acute pancreatitis. Pancreas 2014, 43:82-87
41. Hussain N, Wu F, Zhu L, Thrall RS, Kresch MJ: Neutrophil apoptosis during the development and resolution of oleic acid-induced acute lung injury in the rat. Am J Respir Cell Mol Biol 1998, 19:867-874

42. Moriuchi H, Zaha M, Fukumoto T, Yuizono T: Activation of polymorphonuclear leukocytes in oleic acid-induced lung injury. Intensive Care Med 1998, 24:709-715

43. Abu Hilal M, Armstrong T: The impact of obesity on the course and outcome of acute pancreatitis. Obes Surg 2008, 18:326-328

44. Papachristou GI, Papachristou DJ, Avula H, Slivka A, Whitcomb DC: Obesity increases the severity of acute pancreatitis: performance of APACHE-O score and correlation with the inflammatory response. Pancreatology 2006, 6:279-285

45. Porter KA, Banks PA: Obesity as a predictor of severity in acute pancreatitis. Int J Pancreatol 1991, 10:247-252

46. Shin KY, Lee WS, Chung DW, Heo J, Jung MK, Tak WY, Kweon YO, Cho CM: Influence of obesity on the severity and clinical outcome of acute pancreatitis. Gut Liver 2011, 5:335-339

47. O'Leary DP, O'Neill D, McLaughlin P, O'Neill S, Myers E, Maher MM, Redmond HP: Effects of abdominal fat distribution parameters on severity of acute pancreatitis. World J Surg 2012, 36 : $1679-1685$

48. Sempere L, Martinez J, de Madaria E, Lozano B, Sanchez-Paya J, Jover R, Perez-Mateo M: Obesity and fat distribution imply a greater systemic inflammatory response and a worse prognosis in acute pancreatitis. Pancreatology 2008, 8:257-264

49. Evans AC, Papachristou GI, Whitcomb DC: Obesity and the risk of severe acute pancreatitis. Minerva Gastroenterol Dietol 2010, 56: $169-179$

50. Chen SM, Xiong GS, Wu SM: Is obesity an indicator of complications and mortality in acute pancreatitis? An updated meta-analysis. J Dig Dis 2012, 13:244-251

51. Gukovskaya AS, Mouria M, Gukovsky I, Reyes CN, Kasho VN, Faller LD, Pandol SJ: Ethanol metabolism and transcription factor activation in pancreatic acinar cells in rats. Gastroenterology 2002, 122:106-118

52. Werner J, Saghir M, Fernandez-del Castillo C, Warshaw AL, Laposata M: Linkage of oxidative and nonoxidative ethanol metabolism in the pancreas and toxicity of nonoxidative ethanol metabolites for pancreatic acinar cells. Surgery 2001, 129:736-744

53. Haber P, Wilson J, Apte M, Korsten M, Pirola R: Individual susceptibility to alcoholic pancreatitis: still an enigma. J Lab Clin Med 1995, 125:305-312

54. Dufour MC, Adamson MD: The epidemiology of alcohol-induced pancreatitis. Pancreas 2003, 27:286-290

55. Patel K, Trivedi RN, Durgampudi C, Noel P, Cline RA, DeLany JP, Navina S, Singh VP: Lipolysis of visceral adipocyte triglyceride by pancreatic lipases converts mild acute pancreatitis to severe pancreatitis independent of necrosis and inflammation. Am J Pathol 2015 , $185: 808-819$

56. Printz H, Saluja A, Leli U, Sengupta A, Steer M: Effects of hemorrhagic shock, aspirin, and ethanol on secretagogue-induced experimental pancreatitis. Int J Pancreatol 1990, 6:207-217

57. Saluja AK, Lu L, Yamaguchi Y, Hofbauer B, Runzi M, Dawra R, Bhatia M, Steer ML: A cholecystokinin-releasing factor mediates ethanol-induced stimulation of rat pancreatic secretion. J Clin Invest 1997, 99:506-512

58. Wilson JS, Korsten MA, Apte MV, Thomas MC, Haber PS, Pirola RC: Both ethanol consumption and protein deficiency increase the fragility of pancreatic lysosomes. J Lab Clin Med 1990, 115: 749-755

59. Haber PS, Wilson JS, Apte MV, Korsten MA, Pirola RC: Chronic ethanol consumption increases the fragility of rat pancreatic zymogen granules. Gut 1994, 35:1474-1478

60. Goncalves-de-Albuquerque CF, Burth P, Silva AR, de Moraes IM, de Jesus Oliveira FM, Santelli RE, Freire AS, Bozza PT, YounesIbrahim M, de Castro-Faria-Neto HC, de Castro-Faria MV: Oleic acid inhibits lung $\mathrm{Na} / \mathrm{K}$-ATPase in mice and induces injury with lipid 
body formation in leukocytes and eicosanoid production. J Inflamm (Lond) 2013, 10:34

61. Inoue $\mathrm{H}$, Nakagawa $\mathrm{Y}$, Ikemura M, Usugi E, Nata M: Molecularbiological analysis of acute lung injury (ALI) induced by heat exposure and/or intravenous administration of oleic acid. Leg Med (Tokyo) 2012, 14:304-308

62. Vadasz I, Morty RE, Kohstall MG, Olschewski A, Grimminger F, Seeger W, Ghofrani HA: Oleic acid inhibits alveolar fluid reabsorption: a role in acute respiratory distress syndrome? Am J Respir Crit Care Med 2005, 171:469-479

63. Wu RP, Liang XB, Guo H, Zhou XS, Zhao L, Wang C, Li RS: Protective effect of low potassium dextran solution on acute kidney injury following acute lung injury induced by oleic acid in piglets. Chin Med J (Engl) 2012, 125:3093-3097

64. Ishola DA Jr, Post JA, van Timmeren MM, Bakker SJ, Goldschmeding R, Koomans HA, Braam B, Joles JA: Albuminbound fatty acids induce mitochondrial oxidant stress and impair antioxidant responses in proximal tubular cells. Kidney Int 2006, 70: 724-731

65. Diczfalusy MA, Bjorkhem I, Einarsson C, Hillebrant CG, Alexson SE: Characterization of enzymes involved in formation of ethyl esters of long-chain fatty acids in humans. J Lipid Res 2001, 42: $1025-1032$
66. Kaphalia BS, Ansari GA: Purification and characterization of rat pancreatic fatty acid ethyl ester synthase and its structural and functional relationship to pancreatic cholesterol esterase. J Biochem Mol Toxicol 2003, 17:338-345

67. Kaphalia BS, Mericle KA, Ansari GA: Mechanism of differential inhibition of hepatic and pancreatic fatty acid ethyl ester synthase by inhibitors of serine-esterases: in vitro and cell culture studies. Toxicol Appl Pharmacol 2004, 200:7-15

68. Westkaemper RB, Abeles RH: Novel inactivators of serine proteases based on 6-chloro-2-pyrone. Biochemistry 1983, 22: $3256-3264$

69. Gelb MH, Abeles RH: Mechanism of inactivation of chymotrypsin by 3-benzyl-6-chloro-2-pyrone. Biochemistry 1984, 23:6596-6604

70. Ballantyne CM, Braeckman RA, Soni PN: Icosapent ethyl for the treatment of hypertriglyceridemia. Expert Opin Pharmacother 2013, 14:1409-1416

71. Bookstaff RC, Stuard SB, Ward SR, Pesik PK, Henwood SM: The safety of ethyl oleate is supported by a 91-day feeding study in rats. Regul Toxicol Pharmacol 2004, 39:202-213

72. Bookstaff RC, PaiBir S, Bharaj SS, Kelm GR, Kulick RM, Balm TK, Murray JV: The safety of the use of ethyl oleate in food is supported by metabolism data in rats and clinical safety data in humans. Regul Toxicol Pharmacol 2003, 37:133-148 